\title{
Parental Evaluation of a Telemonitoring Service for Children with Type 1 Diabetes
}

\author{
E. Losiouk ${ }^{1 *}$, G. Lanzola ${ }^{1 *}$, S. Del Favero ${ }^{2 *}$, F. Boscari ${ }^{3}$, M. Messori ${ }^{4}$, I. Rabbone ${ }^{5}$, R. \\ Bonfanti $^{6}$, A. Sabbion ${ }^{7}$, D. lafusco ${ }^{8}$, R. Schiaffini ${ }^{9}$, R. Visentin ${ }^{2}$, S. Galasso ${ }^{3}$, F. Di Palma ${ }^{4}$, D. \\ Chernavvsky $^{10}$, L. Magni ${ }^{4}$, C. Cobelli ${ }^{2 \star}$, D. Bruttomesso ${ }^{3}$, S. Quaglini ${ }^{1 *}$
}

\begin{abstract}
Introduction: In the past years, we developed a telemonitoring service for young patients affected by Type 1 Diabetes. That service provides data to the clinical staff and offers an important tool to the parents, that are able to oversee in real time their children. The aim of this work was to analyze the parents' perceived usefulness of the service. Methods: The service was tested by the parents of 31 children enrolled in a seven-day clinical trial during a summer camp. To study the parents' perception we proposed and analyzed two questionnaires. A baseline questionnaire focused on the daily management and implications of their children's diabetes, while a post-study one measured the perceived benefits of telemonitoring. Questionnaires also included free text comment spaces. Results: Analysis of the baseline questionnaires underlined the parents' suffering and fatigue: $51 \%$ of total responses showed a negative tendency and the mean value of the perceived quality of life was 64.13 in a $0-100$ scale. In the post-study questionnaires about half of the parents believed in a possible improvement adopting telemonitoring. Moreover, the foreseen improvement in quality of life was significant, increasing from 64.13 to 78.39 ( $p$-value $=0.0001$ ). The analysis of free text comments highlighted an improvement in mood, and parents' commitment was also proved by their willingness to pay for the service (median=200 euro/year). Discussion: A high number of parents appreciated the telemonitoring service and were confident that it could improve communication with physicians as well as the family's own peace of mind.
\end{abstract}

\section{Keywords}

Home telecare; ehealth; Self care; Telemedicine; Telemetry

\section{Introduction}

Technology for managing Type 1 Diabetes Mellitus (T1DM) has deeply evolved over time. Patients check their Blood Glucose Level (BGL) concentration either taking finger pricks or using minimally invasive subcutaneous sensors for Continuous Glucose Monitoring (CGM) [1]. Insulin that was once administered only through regular injections may now be continuously delivered also in subcutaneous tissues using wearable pumps [2]. Despite the advances in diabetes technology, the patient is still responsible for adjusting his therapy considering external events (e.g. meals, physical exercise, stress, etc.) and large research efforts have been recently directed to develop an Artificial Pancreas (AP), a system for automating BGL control via closed-loop insulin modulation based on CGM readings [3, 4].

In case of pediatric patients T1DM poses additional challenges. The young age of those patients causes a great concern in parents, especially when children are away from home and manage the treatment on their own [5]. One of the main fears felt by parents is the occurrence of hypoglycemia episodes. Those may quickly develop as the result of a poor management when the child is at school or practicing sports. Thus the daily management of the disease negatively affects both children and parents: the former mainly face physical and emotional effects [6], while the latter, in addition to the emotional concern, suffer three different stress levels. At the lowest one the causes are the everyday activities aimed at improving the children's health care; the medium stress level develops as the parents realize that T1DM is a constant element affecting family life and decisions; finally at the highest level is the traumatizing experience occurring

\footnotetext{
*Authors equally contributed to this study.

${ }^{1}$ Department of Electrical, Computer and Biomedical Engineering, University of Pavia, Pavia, Italy

${ }^{2}$ Department of Information Engineering, University of Padova, Padova, Italy

${ }^{3}$ Unit of Metabolic Diseases, Department of Internal Medicine-DIMED, University of Padova, Padova, Italy

${ }^{4}$ Department of Civil Engineering and Architecture, University of Pavia, Pavia, Italy

${ }^{5}$ Department of Pediatrics, University of Torino, Torino, Italy

${ }^{6}$ Pediatric Department and Diabetes Research Institute, Scientific Institute, Hospital San Raffaele, Milano, Italy

${ }^{7}$ Regional Center for Pediatric Diabetes, Clinical Nutrition \& Obesity, Department of Life \& Reproduction Sciences, University of Verona, Verona, Italy

${ }^{8}$ Department of Pediatrics, Second University of Napoli, Napoli, Italy

'Unit of Endocrinology and Diabetes, Bambino Gesu', Children's Hospital, Roma, Italy

${ }^{10}$ Center for Diabetes Technology, University of Virginia, Charlottesville, VA, USA
}

\section{Corresponding author:}

Eleonora Losiouk Department of Electrical, Computer and Biomedical Engineering University of Pavia Via Ferrata 5, 27100 Pavia, Italy

Email: eleonora.losiouk01@ateneopv.it 
whenever any complication develops in children [7]. Parents may also feel guilty about the appropriateness of the care they are giving to their children [8] and get anxious or even depressed for that situation [9].

Telemedicine, that is being increasingly adopted for the provision of medical services to outpatients [10,11, 12], may be leveraged for mitigating the abovementioned problems [13]. In this paper we evaluate the parents' perception of a telemedicine service, notably a telemonitoring one (TM), that is able to oversee in real time the physiological parameters of their children when they are not under their direct control, such as when they are away from home or overnight. This kind of service has been offered to parents of T1DM children enrolled in a clinical trial accomplished during a summer camp held in 2015 [14] and aimed at controlling BGL through the use of an AP system on children.

\section{Methods}

\section{The Telemonitoring Service}

The TM service, on which this manuscript focuses, is implemented as a web application that was made available to each parent, allowing him/her to oversee his/her child during the camp. The TM main screen is shown in Figure 1. It offers a summary of the child conditions in the upper left panel by reporting the most relevant information: the last BGL reading, its trend and a hypo-/ hyper-risk assessment. The central panel includes a chart with a number of physiological variables, including: glucose concentration measured by the CGM every 5 minutes, insulin delivery rates, meal intake, and risk assessments throughout the period displayed. It is possible to choose which variables to display using the checkboxes above the panel. The chart also depicts information about devices' functioning (e.g. closed-loop, open-loop, etc.). Alternate views, selectable through tabs, offer textual information not suitable for charting (e.g. settings, logs, messages, etc.). The TM service was also used by the study team to monitor in real-time the trial, allowing a comprehensive data collection and analysis and providing a valuable support for therapy adjustments. Both these features were illustrated to the parents.

The TM service was inspired by some authors' previous experiences [15]. It was first developed to enforce safety on diabetes patients [16] undergoing a therapy administered through the AP. After an initial tuning phase on inpatients [17], the TM service has been used throughout several experiments enrolling patients at their domiciles $[18,19]$.

\section{The Clinical Trial}

Data analyzed in this paper were collected during a randomized crossover clinical trial assessing the effectiveness of BGL control achieved through the use of an AP in pediatric prepubertal patients. Considering previous studies [20, 21, 22, 23], this was the first time that a closed-loop insulin therapy, based on the Modular Model Predictive Control algorithm [24, 25], was compared to the manually controlled therapy in prepubertal children. The trial was performed at a summer camp in Bardonecchia, a small village located in the Northern part of Italy. It lasted for 8 days enrolling 31 patients aged 5 to 9 years selected by pediatric diabetologists practicing at 5 different major centers in Italy.

As soon as the patients were admitted at the camp, they were randomly assigned to one of the two groups: one group used the AP in the first part of the study and the manually controlled therapy in the second, while the other group did the opposite. Both study parts lasted for 3 days (72 hours) and were separated by a 1-day wash-out period. The clinical results of the study can be found in [14]. The 31 children enrolled in the clinical trial were accompanied by 21 single parents and 10 parent couples. The TM service was available only during the AP segment of the study, i.e. only for 3 days.

\section{The Survey Questionnaires}

To assess the users' perception of the service, two questionnaires were proposed to the parents attending the camp: a first one just before starting to use the AP system with the associated TM service and a second one after having experimented its use.

Baseline questionnaire The main purpose of this questionnaire, that is reported in the Appendix and has been partially inspired by a previous work [5], was the definition of a baseline for the feelings related to the daily management of diabetic children and for the impact of the disease on the Perceived Quality of Life (PQL).

Post-study questionnaire The post-study questionnaire, that is also available in the Appendix and has been partially inspired by previous works [26, 27], aimed to capture the parents' perception about the usefulness of the TM service. Besides questions concerning the parents experience and their willingness to use the TM service in the future, the post-study questionnaire also asked parents to consider the responses previously provided in the baseline questionnaire and to revise those affected by the use of the TM service. The Likert scaling method [28] was adopted for some of the questions.

\section{Statistical Analysis on questionnaire data}

Questionnaire responses were analyzed using the $R$ statistical tool [29]. Center, parents' gender, children's gender and children's age were investigated as explanatory variables of the questionnaires' scores. Kruskal-Wallis and Wilcoxon tests were used to check differences among the groups identified according to the four variables above. In case of a statistically significant analysis of variance, Wilcoxon test was executed on each pair of groups. The analyses were conducted both on the responses provided to each question and on the sum of the responses to questions belonging to the same section. All the possible responses for multiple-choice questions followed the same ordinal scale weighted with a numerical score ranging from 1 (very negative feeling) to 5 (very positive feeling). Spearman's correlation analysis was used for identifying the relationship between two numerical variables. Baseline vs. post-study comparisons of numerical values were performed using the Wilcoxon test for paired data. A stepwise multiple regression analysis was used to identify possible independent predictors of PQL.

Finally, we used the SentiStrength tool [30] to analyze free text comments reported in the questionnaires through 


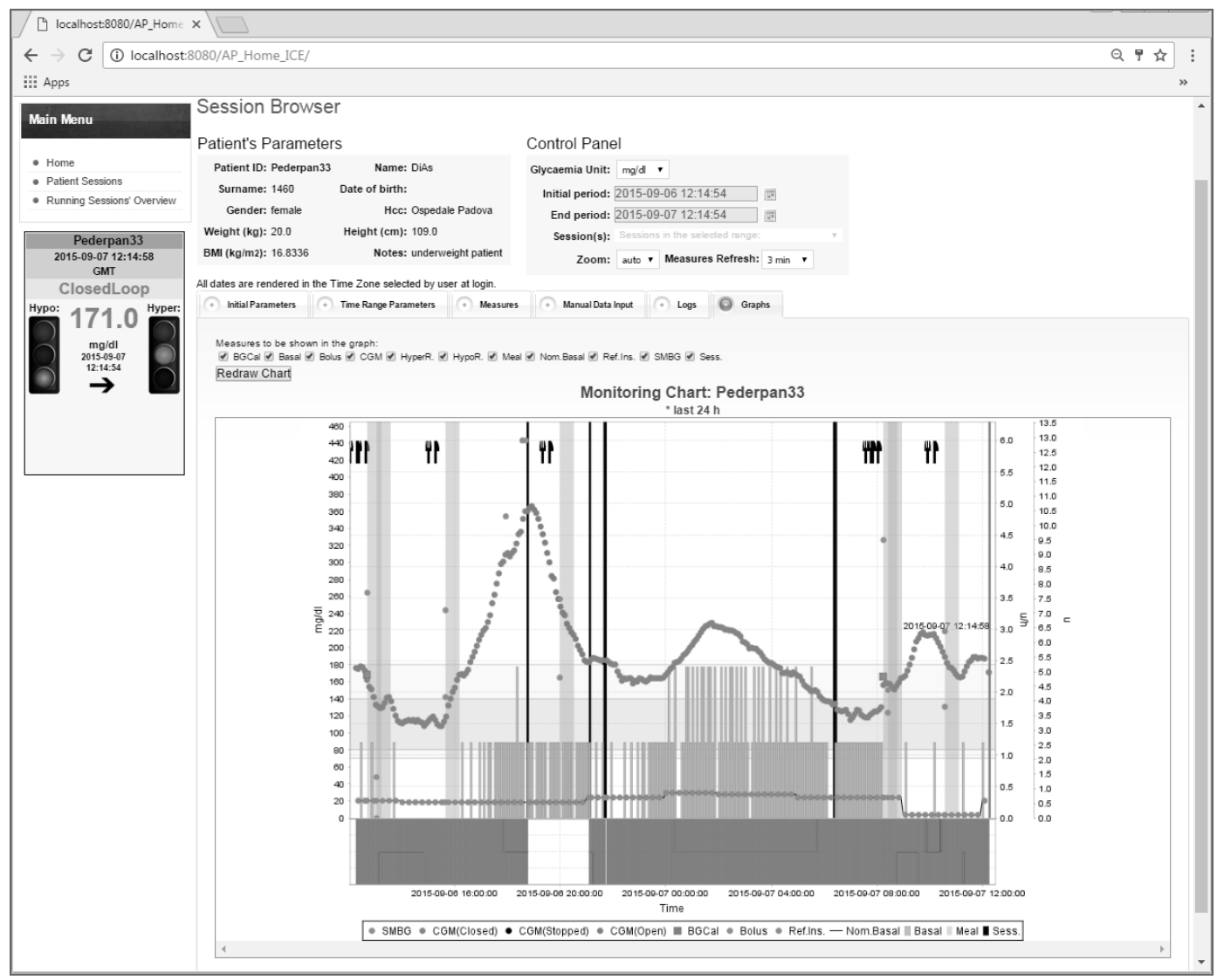

Figure 1. The main screen of the TM service.

Sentiment Analysis. This is a branch of text mining dealing with the computational processing of opinion, sentiment, and subjectivity expressed in natural language.

\section{Results}

Overall 41 baseline and 38 post-study questionnaires were collected. That difference is due to one child dropping out and some parents of children in the second arm leaving the camp soon after the closed-loop session and before questionnaires administration. Parents were both fathers $(n=16)$ and mothers $(n=25)$ of female $(n=11)$ and male $(n=20)$ diabetic children from five to nine years old $(5 y r s=3$; $6 y r s=4 ; 7 y r s=10 ; 8 y r s=10 ; 9 y r s=4 ;$ median $=7.5 y r s ; 1 \mathrm{st}-3 \mathrm{rd}$ quartile $=6.98-8.24 \mathrm{yrs}$ ). Families came from five different locations in Italy: Milano ( $n=8)$, Napoli $(n=4)$, Roma $(n=3)$, Torino $(n=10)$ and Verona $(n=6)$.

\section{Baseline questionnaire analysis}

We first analyzed Section 1 to understand how the parents' life is affected by the disease of their child. Classification of the responses into positive ("Never" or "Rarely") or negative ("Sometimes", "Often", "Very Often") tendencies revealed nearly equal distributions (49\% positive tendency; $51 \%$ negative tendency). Figure 2 provides a general overview of the positive responses, stratified according to four explanatory variables.

Families coming from different locations seemed to feel different levels of burden, as illustrated in Figure 3. The median score of all questions in Section 1 (encompassing 8 questions totaling [0-40]) varies from 21 in Verona to
32 in Milano and the analysis of variance on the total score showed a p-value of 0.009 . Responses provided by fathers and mothers did not show any statistically significant difference. Children's gender also did not affect parents' responses, while children's age turned out to be positively and significantly correlated with the total score of the responses, as shown in Figure 4. Finally, parents pointed out fatigue as one of the most severe consequences of managing diabetes every day, together with the continuous rapid change of their children's health status (questions $1 d$ and $1 f$ ).

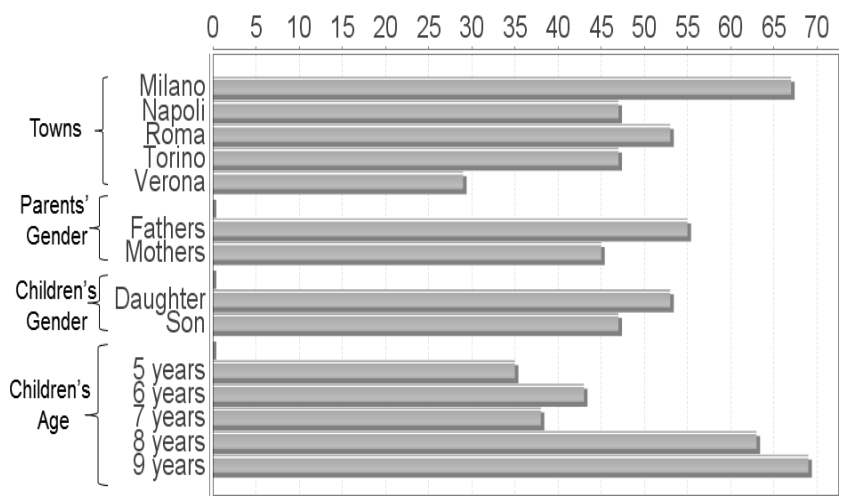

Figure 2. Baseline questionnaire, Section 1: percentages of responses expressing a positive tendency (i.e. "Never" or "Rarely") stratified according to explanatory variables.

In the second section, parents were asked to rate their PQL on a 0-100 scale. The mean PQL value was 64.13 and no statistically significant differences were found among 


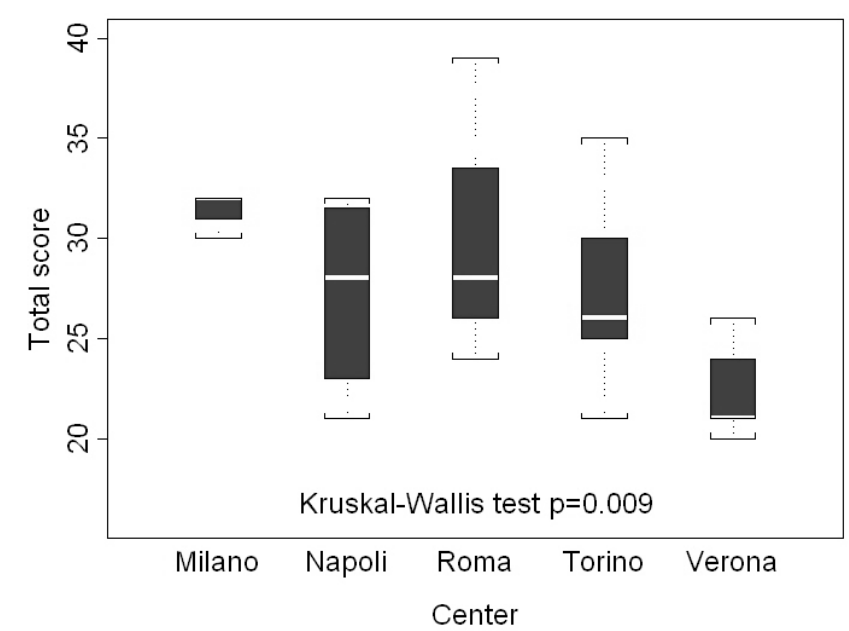

Figure 3. Baseline questionnaire, Section 1: total scores according to the five centers.

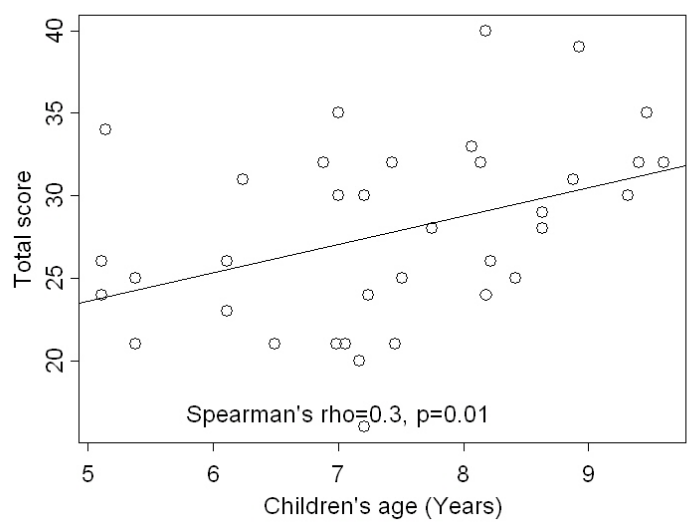

Figure 4. Baseline questionnaire, Section 1: correlation between total score and children's age.

groups. With a borderline statistical significance $(\mathrm{p}=0.07)$, fathers showed a more positive attitude with respect to mothers.

At univariate regression analysis, the responses to the following questions were identified as significant predictors of PQL: "Our family gives up a lot of things (e.g. travelling together for long periods)" ( $1 a$; p-value $=0.015)$, "In taking care of my son I do not have enough time for other family members" ( $1 b$; p-value=0.008), "I feel like I'm living on a roller coaster: in crisis when my son is sick, calm when he feels good" ( $1 d$; p-value=0.01), "I feel tired" ( $1 f$; p-value $=0.006)$ and "We give up seeing family and friends" $(1 g ; \mathrm{p}$-value $=0.03)$. However, a stepwise multiple regression analysis including parents' and children's gender together with children's age, revealed that only "fatigue" and "having a male child" are retained in the model as significant independent aspects that affect PQL (multiple R squared=0.29).

\section{Post-study questionnaire analysis}

In the first section parents were asked to assess whether TM could improve the communication with the health care staff. Overall we observed that in $85 \%$ of the responses they expressed their agreement, in $12 \%$ they expressed neutrality and only in $3 \%$ they expressed disbelief.

Considering the four explanatory variables, only the children's age seemed to affect parents' responses: the smoothing curve obtained with a locally-weighted polynomial regression in Figure 5 shows higher scores when children enter the school-age.

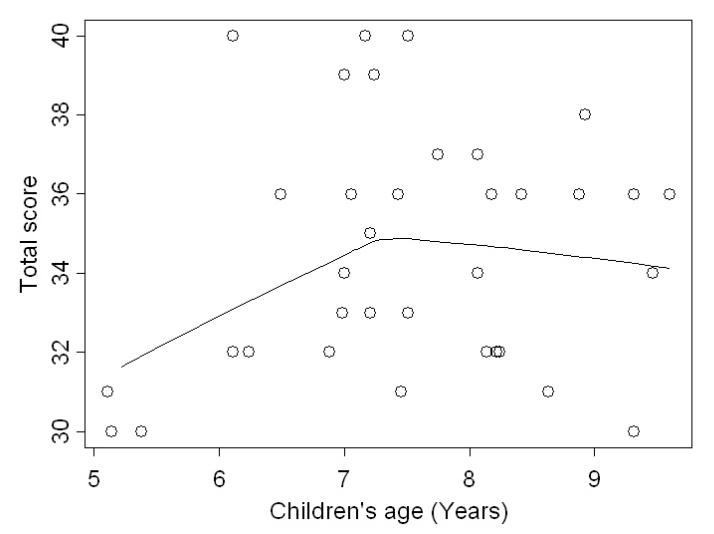

Figure 5. Post-study questionnaire, Section 1: total score according to children's age.

According to the parents the possible advantages of using the TM are: "Improves remote control by sending notifications about emergencies (e.g., by sending alarms in case of hypoglycemia events)", "Improves the exchange of medical information between patient and family members", "Improves family's serenity when someone is away from home" and "Allows physicians and hospital to take care of their patients in a better way" (median $=5$, on the ordinal scale 1-5), followed by "Substitutes paper material for communicating the clinical data", "Decreases the costs due to visits, controls and phone calls to the hospital" and "Decreases worries" (median=4) and "Decreases the number of controls required in the hospital" (median=3).

Concerning the willingness to pay, the median value is 200 euro/year, ranging from 0 to 3000 euro/year. Considering the explanatory variables, no statistically significant differences were found, except for the towns ( $\mathrm{p}$-value $=0.005$ ), with Verona and Napoli being the locations with the lowest willingness to pay. Independently from the amount of money that parents were willing to pay, all of them expressed their desire to use TM.

The fourth section was focused on understanding which aspect of diabetes management could be improved by the TM. Parents were asked to repeat Section 1 of the baseline questionnaire after experiencing the TM service, indicating if its use could improve, worsen or was irrelevant for each of the 8 items previously answered. None of the parents said that using TM could worsen the management, $49.65 \%$ expressed a potential improvement, while $50.35 \%$ said that the TM was deemed to have no impact. However, parents' "fatigue", which emerged through the baseline questionnaire as the worst effect of diabetes management, was considered the most improvable item through a daily usage of the TM.

In the last section, we again asked the parents to provide an estimate of their PQL if the TM was regularly available 
in their daily life. The mean value was 78.39 , which was significantly higher than in the baseline questionnaires ( $p$ value $=0.0001$ )

PQL improvement was significantly correlated with responses to questions "Our family gives up a lot of things (e.g. travelling together for long periods)" (4a; pvalue $=0.01)$, "We give up seeing family and friends" $(4 g$; $\mathrm{p}$-value $=0.01$ ) and "We do not have much desire to go out" $(4 h ; \mathrm{p}$-value $=0.05)$. A stepwise multiple regression analysis identified improvements in $4 a$ and $4 g$ as the only independent factors positively affecting PQL (multiple R squared=0.32). This is explained by the highest correlation found between questions $4 a$ and $4 h$ (p-value $<<0.05$ ).

Finally, comparing the sentiment analysis scores achieved by processing the comments in the free text sections in both questionnaires, we found a significant decrease of negative scores (median and quartiles of the difference between positive and negative scores: $-1[-2 ; 0]$ baseline; $1[0.75 ; 2]$ post-study; -value=0.028).

\section{Discussion}

Technology presently offers solutions supporting remote monitoring and patient education in the disease's management $[31,32]$. The aim of our study was to evaluate how a TM service could help parents of children affected by T1DM in managing the disease, reassuring them and improving their PQL.

Responses provided to the baseline questionnaire gave a general overview of the parents' feeling about diabetes. Studies focusing on the parents' feelings identified three different stressful conditions: (a) low self-efficacy in helping with the disease, (b) the occurrence of hypoglycemia events, and (c) their responsibility in the overall management of diabetes [33]. Moreover, the level of responsibility of family members, and the burden of their stress, is inversely related to the child's age, since the younger the patient is, the more attention he requires. This was confirmed by our analysis, since parents of young children actually declared a more negative attitude in coping with diabetes. The borderline result about the more positive attitude of fathers with respect to mothers is in line with other studies [34], possibly suggesting that fathers are less emotionally involved since they are usually busier and spend more time outside.

Besides acquiring the baseline of parents' feelings before the intervention, we also had to select an outcome for measuring the users' perception of our TM. A previous review concerning telemedicine systems identified the following possible outcomes: BGL monitoring, improvements in glycemic control, patient satisfaction and improvements in self-management [35]. We selected the parents' satisfaction as the main outcome for evaluating the TM considering that those are responsible for enacting the children's treatment. BGL monitoring and glycemic control were discarded as they were the primary outcomes of the underlying clinical trial, the goal of which was to assess the efficacy of an AP running in closed-loop in comparison with the manually controlled therapy. Even self-management was unsuitable since the therapy was managed by the AP and closely supervised by the clinical and bioengineering staff. The parents' satisfaction was assessed through the administration of a post-study questionnaire as already done in previous studies [36, 37, 38].

Results showed that most of the parents believed in a possible improvement for what concerns the interaction with the healthcare staff, while half of them also believed on an enhancement in their personal serenity. Neutrality and disbelief also conveyed some skepticism about the possible reduction in control visits and their associated costs. This may be due to the increased serenity felt by parents if children are visited face-to-face. The parents of the oldest children appreciated TM more than others. The reason may be found in the greater wish of independence and self-management shown by grown-up children, and by the consequent need for parents to find an alternative way to stay updated with their children's status without being too obtrusive [35]. This is supported by responses indicating that parents were highly confident about the support provided by TM to the family own serenity when children are away. Moreover, we found a correlation between the appreciation of the TM shown by the parents and the school age. As a matter of fact, in Italy education starts when children are 6 years old, and as soon as children start going to school they also begin to use the technology (e.g. smartphone apps) as a means of staying in touch with the family. This in turn leads parents to better appreciate the TM potential for reporting on the disease status of their children, highlighting the advantages of the service.

To sum up, despite our study highlighted some skepticism about the usefulness of the TM service by some parents, it also showed their interest in using it as a means of improving the management of T1DM and the communication with the health care staff. The interest in the service was also emphasized by the responses of $61 \%$ of the parents willing to pay a fee for it. Given that the Italian national healthcare service grants most services for free, this is an indirect proof of the perceived usefulness of the TM. The parents' positive attitude towards the TM matches their satisfaction and confidence in the AP technology, as emerged from a specific investigation performed through the administration of questionnaires and structured interviews during the same camp [39].

Finally, the main limitation affecting our study is that parents were provided with the TM for a very short period of time in an unusual context of use, such as a clinical trial performed at a resort village. Due to this limitation, the perceived usefulness measured during this trial may not be directly correlated with the actual one. Thus a next step could envision extending the TM use over a longer time frame, as in a home trial, to test the system in a context closer to the real life exploiting electronic means for questionnaire administration [40].

\section{Acknowledgements}

The authors would like to thank all the people that took part in the clinical trial. Among those: Roberta Calore and Yenny Leal as camp engineers; Alfonso Galderisi, Valeria Vallone, Davide Tinti, Andrea Rigamonti, Marco Marigliano, Angela Zanfardino and Novella Rapini as camp physicians; Alda Troncone as camp psychologist and Angelo Avogaro as chief of the Padova unit. Moreover, the authors thank the patients 
and their families. We also thank Claudia Scannapieco for her support in improving the English language expression.

This work was partially supported by the Ministero dell'Istruzione, Universita' e Ricerca (Italian Ministry of Education, Universities and Research) through the project Learn4AP: Patient-Specific Models for an Adaptive, FaultTolerant Artificial Pancreas (initiative "SIR: Scientific Independence of young Researchers", project ID: RBSI14JYM2) and through the project "FORGETDIAB: Forget Diabetes: Adaptive Physiological Artificial Pancreas" (initiative "PRIN: Progetti di Ricerca di Interesse Nazionale ", project ID: 2015PJ28EP_001). Data collection was possible thanks to the support of private donors and associations for patients with diabetes. The Italian Research Foundation Societa' Italiana Diabetologia provided administrative support.

\section{References}

[1] Lane J, Shivers J and Zisser H. Continuous glucose monitors: current status and future developments. Curr Opin Endocrinol Diabetes Obes 2013; 20(2): 106-111.

[2] Shashaj B and Sulli N. Difference in insulin usage patterns with pubertal development in children with type 1 diabetes during transition from multiple daily injections to continuous subcutaneous insulin infusion (csii) and through the csii treatment. Diabetes Technol Ther 2009; 11(12): 767-774.

[3] Cobelli C, Renard E and Kovatchev B. Artificial pancreas: Past, present, future. Diabetes 2011; 60(11): 2672-2682.

[4] Thabit H and Hovorka R. Coming of age: the artificial pancreas for type 1 diabetes. Diabetologia 2016; 59(9): 1795-1805.

[5] Helgeson V, Becker D, Escobar O et al. Families with children with diabetes: Implications of parent stress for parent and child health. J Pediatr Psychol 2012; 37(4): 467-478.

[6] Hesketh K, Wake M and Cameron F. Health-related quality of life and metabolic control in children with type 1 diabetes: a prospective cohort study. Diabetes Care 2004; 27(2): 415-20.

[7] Kobos E and Imiela J. Factors affecting the level of burden of caregivers of children with type 1 diabetes. Appl Nurs Res 2015; 28(2): 142-149.

[8] Coffey J. Parenting a child with chronic illness: a metasynthesis. Pediatr Nurs 2006; 32(1): 51-59.

[9] Malerbi F, Negrato C and Gomes M. Assessment of psychosocial variables by parents of youth with type 1 diabetes mellitus. Diabetol Metab Syndr 2012; 4: 48.

[10] Yang YT, Iqbal U, Ching JY et al. Trends in the growth of literature of telemedicine: A bibliometric analysis. Comput Methods Programs Biomed 2015; 122(3): 471479.

[11] Ekeland A, Bowes A and Flottorp S. Effectiveness of telemedicine: A systematic review of reviews. Int $J$ Med Inform 2010; 79(11): 736-771.
[12] Finet P, Le Bouquin Jeannes R, Dameron $\mathrm{O}$ et al. Review of current telemedicine applications for chronic diseases. Toward a more integrated system? Irbm 2015; 36(3): 133-157.

[13] Lanzola G, Losiouk E, Del Favero S et al. Remote blood glucose monitoring in mhealth scenarios: a review. Sensors 2016; 16(12): 2-16.

[14] Del Favero S, Boscari F, Messori M et al. Randomized summer camp cross-over trial in 5-9 year old children: outpatient wearable artificial pancreas is feasible and safe. Diabetes Care 2016; 39(7): 1180-1185.

[15] Capozzi D and Lanzola G. Utilizing information technologies for lifelong monitoring in diabetes patients. J Diabetes Sci Technol 2011; 5(1): 55-62.

[16] Lanzola G, Capozzi D, Serina $\mathrm{N}$ et al. Bringing the artificial pancreas home: telemedicine aspects. $J$ Diabetes Sci Technol 2011; 5(6): 1381-1386.

[17] Capozzi D and Lanzola G. A generic telemedicine infrastructure for monitoring an artificial pancreas trial. Comput Methods Programs Biomed 2013; 110(3): 343353.

[18] Lanzola G, Scarpellini S, Di Palma F et al. Monitoring artificial pancreas trials through agentbased technologies: A case report. J Diabetes Sci Technol 2014; 8(2): 216-224.

[19] Lanzola G, Toffanin C, Di Palma F et al. Designing an artificial pancreas architecture: the ap@home experience. Med Biol Eng Comput 2015; 53(12): 12711283.

[20] Luijf Y, DeVries J, Zwinderman K et al. Day and night closed-loop control in adults with type 1 diabetes: a comparison of two closed-loop algorithms driving continuous subcutaneous insulin infusion versus patient self-management. Diabetes Care 2013; 36(12): 3882-3887.

[21] Zisser H, Renard E, Kovatchev B et al. Multicenter closed-loop insulin delivery study points to challenges for keeping blood glucose in a safe range by a control algorithm in adults and adolescents with type 1 diabetes from various sites. Diabetes Technol Ther 2014; 16(10): 613-622.

[22] Kropff J, Del Favero S, Place J et al. 2 month evening and night closed-loop glucose control in patients with type 1 diabetes under free-living conditions: a randomised crossover trial. Lancet Diabetes Endocrinol 2015; 3(12): 939-947.

[23] Renard E, Farret A, Kropff J et al. Day and night closed-loop glucose control in patients with type 1 diabetes under free-living conditions: Results of a single-arm 1-month experience compared with a previously reported feasibility study of evening and night at home. Diabetes Care 2016; 39(7): 1151-1160. 
[24] Patek S, Magni L, Dassau E et al. Modular closedloop control of diabetes. IEEE Trans Biomed Eng 2012; 59(11): 2986-2999.

[25] Toffanin C, Messori M, Di Palma F et al. Artificial pancreas: model predictive control design from clinical experience. J Diabetes Sci Technol 2013; 7(6): 14701483.

[26] Mairinger T. Annex VII: Questionnaire on Telemedicine. Handbook of Telemedicine, volume 54. O Ferrer-Roca, M Sosa-Iudicissa, 1998. ISBN 978-905199-413-1:print 978-1-60750-898-4:online.

[27] Yip M, Chang A, Chan J et al. Development of the telemedicine satisfaction questionnaire to evaluate patient satisfaction with telemedicine: a preliminary study. J Telemed Telecare 2003; 9(1): 46-50.

[28] Camparo J. A geometrical approach to the ordinal data of Likert scaling and attitude measurements: The density matrix in psychology. J Math Psychol 2013; 57(1-2): 29-42.

[29] R Development Core Team. R: A Language and Environment for Statistical Computing. R Foundation for Statistical Computing, Vienna, Austria, 2008. ISBN 3-900051-07-0.

[30] Thelwall M. Heart and soul: Sentiment strength detection in the social web with sentistrength, 2017. Cyberemotions: Collective emotions in cyberspace.

[31] Capozzi D and Lanzola G. An agent-based architecture for home care monitoring and education of chronic patients. In IEEEXplore; Proceedings of the IEEE Conference on Complexity in Engineering, COMPENG'10. IEEE, IEEEXplore, pp. 138-140.

[32] Lanzola G, Ginardi G, Russo P et al. Delivering and assessing learning material through gquest: A case study on patient education. Int J Mobile Blended Learn 2014; 6(3): 52-68.

[33] Streisand R, Swift E, Wickmark T et al. Pediatric parenting stress among parents of children with type 1 diabetes: the role of self-efficacy, responsibility, and fear. J Pediatr Psychol 2005; 30(6): 513-521.

[34] Sullivan-Bolyai S, Deatrick J, Gruppuso P et al. Constant vigilance: Mothers' work parenting young children with type 1 diabetes. Pediatr Nurs 2003; 18(1): 21-29.

[35] Guljas R, Ahmed A, Chang $\mathrm{K}$ et al. Impact of telemedicine in managing type 1 diabetes among school-age children and adolescents: an integrative review. Pediatr Nurs 2014; 29(3): 198-204.

[36] Carroll A, DiMeglio L, Stei S et al. Using a cell phone-based glucose monitoring system for adolescent diabetes management. Diabetes Educ 2011; 37(1): 5966.
[37] Chase H, Pearson J, Wightman C et al. Modem transmission of glucose values reduces the costs and need for clinic visits. Diabetes Care 2003; 26(5): 14751479 .

[38] Rami B, Popow C, Horn W et al. Telemedical support to improve glycemic control in adolescents with type 1 diabetes mellitus. Eur J Pediatr 2006; 165(10): 701705 .

[39] Troncone A, Bonfanti R, Iafusco D et al. Evaluating the experience of children with type 1 diabetes and their parents taking part in an artificial pancreas clinical trial over multiple days in a diabetes camp setting. Diabetes Care 2016; 39(12): 2158-2164.

[40] Lanzola G, Ginardi M, Mazzanti A et al. Gquest: Modeling patient questionnaires and administering them through a mobile platform application. Comput Methods Programs Biomed 2014; 117(2): 277-291. 


\section{BASELINE QUESTIONNAIRE}

Section 1. Thinking about the last six months indicate how much the diabetes of your son has affected the following aspects:

\begin{tabular}{|c|c|c|c|c|c|}
\hline & Never & Rarely & Sometimes & Often & Very Often \\
\hline $\begin{array}{l}\text { a. Our family gives up a lot of things (e.g. } \\
\text { travelling together for long periods). }\end{array}$ & $\square$ & $\square$ & $\square$ & $\square$ & $\square$ \\
\hline $\begin{array}{l}\text { b. In taking care of my son I do not have } \\
\text { enough time for other family members. }\end{array}$ & $\square$ & $\square$ & $\square$ & $\square$ & $\square$ \\
\hline c. We often change plans at last. & $\square$ & $\square$ & $\square$ & $\square$ & $\square$ \\
\hline $\begin{array}{l}\text { d. I feel like I'm living on a roller coaster: } \\
\text { in crisis when my son is sick, calm } \\
\text { when he feels good. }\end{array}$ & $\square$ & $\square$ & $\square$ & $\square$ & $\square$ \\
\hline $\begin{array}{l}\text { e. I live for the day and I do not plan } \\
\text { anything for the future. }\end{array}$ & $\square$ & $\square$ & $\square$ & $\square$ & $\square$ \\
\hline f. I feel tired. & $\square$ & $\square$ & $\square$ & $\square$ & $\square$ \\
\hline g. We give up seeing family and friends. & $\square$ & $\square$ & $\square$ & $\square$ & $\square$ \\
\hline h. We do not have much desire to go out. & $\square$ & $\square$ & $\square$ & $\square$ & $\square$ \\
\hline
\end{tabular}

Section 2. Considering the overall effect of diabetes of your child on your well-being, which value on a 0-100 scale do you think best expresses your current quality of life ( 0 is the worst health you can imagine and 100 is the best health you can imagine)?

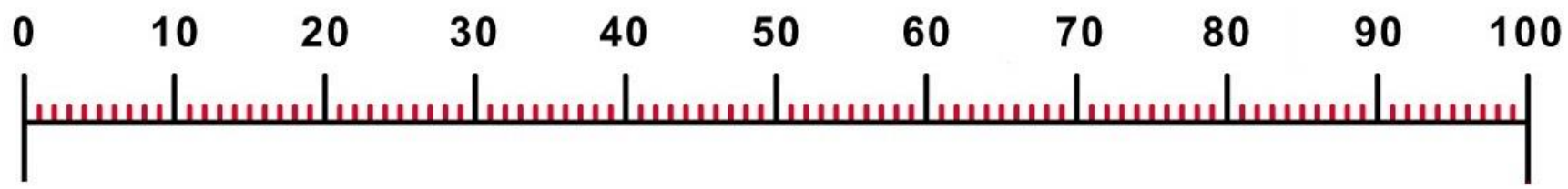


Section 3. Write here your additional comments: 


\section{POST-STUDY QUESTIONNAIRE}

Section 1. What are your expectations about the use of the telemonitoring service?

a. Improves remote control by sending notifications about emergencies (e.g., by sending alarms in case of hypoglycemia events).

b. Improves the exchange of medical information between patient and family members.

c. Improves family's serenity when someone is away from home.

d. Allows physicians and hospital to take care of their patients in a better way.

e. Substitutes paper material for communicating the clinical data.

f. Decreases the number of controls required in the hospital.

g. Decreases the costs due to visits, controls and phone calls to the hospital.

h. Decreases worries.

\begin{tabular}{|c|c|c|c|c|}
$\begin{array}{c}\text { Strongly } \\
\text { agree }\end{array}$ & Agree & Don't know & Disagree & $\begin{array}{c}\text { Strongly } \\
\text { Disagree }\end{array}$ \\
$\square$ & $\square$ & $\square$ & $\square$ & $\square$ \\
$\square$ & $\square$ & $\square$ & $\square$ & $\square$ \\
\hline$\square$ & $\square$ & $\square$ & $\square$ & $\square$ \\
\hline$\square$ & $\square$ & $\square$ & $\square$ & $\square$ \\
\hline$\square$ & $\square$ & $\square$ & $\square$ & $\square$ \\
\hline$\square$ & $\square$ & $\square$ & $\square$ & $\square$ \\
\hline$\square$ & $\square$ & $\square$ & $\square$ & $\square$ \\
\hline$\square$ & $\square$ & $\square$ & $\square$ & $\square$ \\
\hline
\end{tabular}

Section 2. If the system was available in the everyday life:

a. How many times would you use it?

\begin{tabular}{|c|c|c|c|}
\hline Often & Sometimes & Rarely & Never \\
$\square$ & $\square$ & $\square$ & $\square$ \\
\hline
\end{tabular}

b. How much would pay for it (e.g. euro/year)?

\section{Section 3. Which functionalities would you like to have in your personal area?}

\begin{tabular}{|l|c|c|c|}
\hline & Yes & No & Don't know \\
\hline a. Graphs / history of glycaemia values. & $\square$ & $\square$ & $\square$ \\
\hline b. Other statistical analyses. & $\square$ & $\square$ & $\square$ \\
\hline c. Annotations from the physician. & $\square$ & $\square$ & $\square$ \\
\hline d. Other (write here): & \multicolumn{2}{|}{} \\
\hline
\end{tabular}


Section 4. Consider the responses provided in the first section of the baseline questionnaire and express whether the telememonitoring service can affect them in a positive, negative or irrelevant way.

\begin{tabular}{|c|c|c|c|c|c|c|}
\hline & Never & Rarely & Sometimes & Often & $\begin{array}{l}\text { Very } \\
\text { often }\end{array}$ & Effect of the system \\
\hline $\begin{array}{l}\text { a. Our family gives up a lot of things } \\
\text { (e.g. travelling together for long } \\
\text { periods). }\end{array}$ & $\square$ & $\square$ & $\square$ & $\square$ & $\square$ & $\begin{array}{l}\square \text { Improves } \\
\square \text { Worsens } \\
\square \text { Irrelevant }\end{array}$ \\
\hline $\begin{array}{l}\text { b. In taking care of my son I do not } \\
\text { have enough time for other family } \\
\text { members. }\end{array}$ & $\square$ & $\square$ & $\square$ & $\square$ & $\square$ & $\begin{array}{l}\square \text { Improves } \\
\square \text { Worsens } \\
\square \text { Irrelevant }\end{array}$ \\
\hline c. We often change plans at last. & $\square$ & $\square$ & $\square$ & $\square$ & $\square$ & $\begin{array}{l}\square \text { Improves } \\
\square \text { Worsens } \\
\square \text { Irrelevant }\end{array}$ \\
\hline $\begin{array}{l}\text { d. I feel like l'm living on a roller } \\
\text { coaster: in crisis when my son is sick, } \\
\text { calm when he feels good. }\end{array}$ & $\square$ & $\square$ & $\square$ & $\square$ & $\square$ & $\begin{array}{l}\square \text { Improves } \\
\square \text { Worsens } \\
\square \text { Irrelevant }\end{array}$ \\
\hline $\begin{array}{l}\text { e. I live for the day and I do not plan } \\
\text { anything for the future. }\end{array}$ & $\square$ & $\square$ & $\square$ & $\square$ & $\square$ & $\begin{array}{l}\square \text { Improves } \\
\square \text { Worsens } \\
\square \text { Irrelevant }\end{array}$ \\
\hline f. I feel tired. & $\square$ & $\square$ & $\square$ & $\square$ & $\square$ & $\begin{array}{l}\square \text { Improves } \\
\square \text { Worsens } \\
\square \text { Irrelevant }\end{array}$ \\
\hline $\begin{array}{l}\text { g. We give up seeing family and } \\
\text { friends. }\end{array}$ & $\square$ & $\square$ & $\square$ & $\square$ & $\square$ & $\begin{array}{l}\square \text { Improves } \\
\square \text { Worsens } \\
\square \text { Irrelevant }\end{array}$ \\
\hline $\begin{array}{l}\text { h. We do not have much desire to go } \\
\text { out. }\end{array}$ & $\square$ & $\square$ & $\square$ & $\square$ & $\square$ & $\begin{array}{l}\square \text { Improves } \\
\square \text { Worsens } \\
\square \text { Irrelevant }\end{array}$ \\
\hline
\end{tabular}


Section 5. Please, choose a new value expressing your perceived quality of life while imaging a daily use of the telemonitoring service. (on the scale it is reported your previous choice; 0 is the worst health you can imagine and 100 is the best health you can imagine).

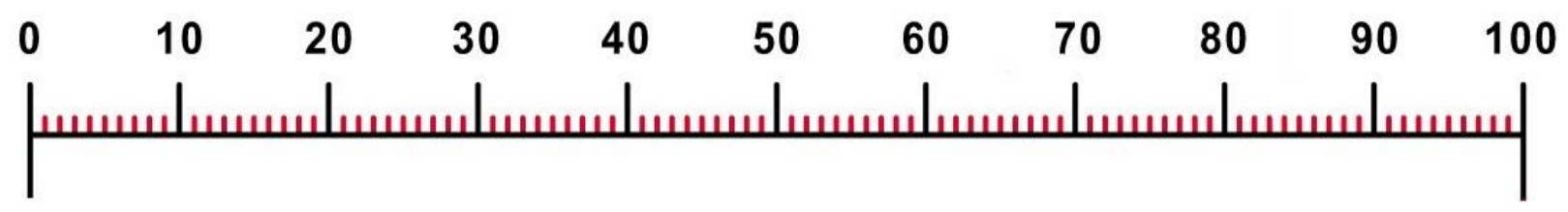

Section 6. Write here your additional comments: 